\title{
As políticas de convivência com a seca: uma análise da implementação do PRONAF no município de Catolé do Rocha-PB
}

\section{To live together policies with drought: a review of the implementation of the city of PRONAF Catolé do Rocha-PB}

\author{
Simone V. Alves ${ }^{1}$; Débora S. S. Martins ${ }^{2}$; Jéssica S. Oliveira ${ }^{3}$, Andressa L. Nóbrega ${ }^{4}$
}

\begin{abstract}
Resumo: A implementação do Programa Nacional de Fortalecimento da Agricultura Familiar (PRONAF) destaca o grande avanço das políticas públicas que estimulam a participação do Estado, em âmbito local e também nacional, no desenvolvimento da agricultura e nas intervenções na realidade rural. $\mathrm{O}$ artigo em questão desenvolve uma análise da implementação do PRONAF no município de Catolé do Rocha no semiárido paraibano, com a finalidade de compreender não apenas como se deu o processo de execução do programa, mas também seus benefícios e impactos socioeconômicos para a população contemplada. Quanto à metodologia utilizada, o tipo de pesquisa caracterizou-se como qualitativa descritiva, optando por um estudo de caso, sendo os dados coletados por meio de entrevista semi-estruturada aos atores locais do programa, sendo exploradas questões inerentes a temática em questão. A análise dos resultados evidencia que na localidade estudada a implementação desse programa não se deu da forma adequada, levando a um mal funcionamento do mesmo, o erro mais aparente seria o fato da concessão de crédito não estar aliada às ações que viabilizam a capacidade de geração de renda para os membros das unidades familiares "pronafianas", o que acaba gerando muitos dos desafios enfrentados na realidade do programa. Apesar disto, os poucos resultados conseguidos no município são vistos como satisfatórios para os beneficiados, já que relatam melhoria em alguns aspectos socioeconômicos da região e trouxe benefícios aos agricultores familiares no município.
\end{abstract}

Palavras-chaves: Políticas públicas, PRONAF, desenvolvimento rural, agricultura familiar.

Abstract: The implementation of the National Program to Strengthen Family Agriculture (PRONAF) highlights the great advancement of public policies that encourage state participation in local and also nationwide, the development of agriculture and rural interventions in reality. The article in question provides an analysis of the implementation of the municipality of PRONAF Catole the Rock in the Paraíba semiarid, in order to understand not only how was the process of implementing the program, but also its benefits and socioeconomic impacts for the population covered. Regarding the methodology used, the type of research was characterized as qualitative descriptive, opting for a case study, with data collected through semistructured program to local actors interview being explored issues related to topic in question. The analysis shows that in the study location that program did not happen properly, leading to malfunctions, the most apparent error would be the fact of granting credit may not be combined with the actions that enable the generation capacity income for members of the "pronafianas" family units, which ends up generating many of the challenges facing the reality of the program. Nevertheless, the few achievements in the city are viewed as satisfactory for the beneficiaries, as reported improvement in some socioeconomic aspects of the region and brought benefits to family farmers in the county.

Keywords: Public policy, PRONAF, rural development, family agriculture.

\footnotetext{
*Autor para correspondência

Recebido para publicação em 03/12/2014; aprovado em 25/12/2014

${ }^{1}$ Graduada em Ciências Agrárias, Mestre em Zootecnia, UFCG, Campos Patos, Patos-PB, simonne_catole@hotmail.com.

${ }^{2}$ Graduada em Biomedicina, Faculdades Integradas de Patos, Patos-PB; suzany_89@hotmail.com.

${ }^{3}$ Graduada em Enfermagem, Faculdades Integradas de Patos, Patos-PB, jessica_catole@ hotmail.com.

${ }^{4}$ Graduada em Enfermagem, Faculdades Integradas de Patos, Patos-PB, andressalacerdanobrega@gmail.com.
} 


\section{INTRODUÇÃO}

A seca é um grave problema que afeta a população nordestina, de maneira mais intensa a população semiárida, comprometendo a vida dos animais e da sociedade, prejudicando a economia da região, sendo um evento climático que já faz parte do convívio da população por diversas gerações. Seu processo de desertificação se caracteriza como um tipo de degradação que se processa em regiões de clima semiárido, relacionado às mudanças climáticas e as atividades humanas, dificultando a vida dos agricultores que retiram do campo o sustento de suas famílias e fazendo-os passar por dificuldades.

Devido a isso, surge a necessidade de se criar e programar políticas públicas que possibilitem a convivência dessa população nesse cenário tão desfavorável, direcionando a atenção da sociedade para cobrança dessas ações que viabilizem a permanência do agricultor no campo.

As políticas públicas que procuram beneficiar a área rural tendem a privilegiar os setores do campo que apresentam maior desenvolvimento e modernização. A agricultura brasileira tem sido esquecida principalmente quando se refere à pequena propriedade e a produção familiar, não suprindo as demandas essenciais à sua sustentabilidade (MATEI, 2006). Tendo como finalidade o fortalecimento das atividades desenvolvidas pelo agricultor familiar, de forma a inseri-lo ao agronegócio, promovendo complementação de renda e agregação de valor à sua produção, foi criado o PRONAF - Programa Nacional de Fortalecimento da Agricultura Familiar (MDA,2012).

Segundo França, (2013), no Brasil, a procura por modernização tecnológica teve como objetivo alcançar o desenvolvimento necessário para que o país pudesse se inserir no mercado mundial. Para que isto pudesse ocorrer, seria necessário racionalizar a produção e as metodologias de trabalho, aumentando a produtividade e ampliando as condições de produção. Dessa forma, essas mudanças afetaram o meio rural, pois as empresas e conglomerados passaram a interferir cada vez mais no processo de produção do campo, com as atividades oriundas da pecuária e agroindústria.

Dessa forma o PRONAF vem como uma política pública que visa auxiliar o homem do campo que tem suas ações voltadas para atender suas necessidades por intermédio da concessão de empréstimos para o desenvolvimento do campo e permanência do mesmo na zona rural. De acordo com Guanziroli (2007), embora o montante de crédito oferecido pelo Governo Federal, através do PRONAF, e o número de famílias beneficiadas tenham crescido, não são apontados os resultados que refletem na melhoria de vida dos agricultores familiares.

Sabendo-se que a agricultura familiar ocupa papel de destaque na organização do espaço agrário paraibano, destaca-se a necessidade de um maior suporte na implementação e gestão de políticas de assistência técnica e creditícia, buscando promover uma maior produtividade neste setor, como também maiores investimentos para proporcionar uma melhor qualidade para o agricultor o que acarretara em produtos de qualidade e com melhores preços no mercado.

De acordo com Tinoco (2005) a agricultura familiar é baseada na utilização da mão-de-obra, no tamanho da propriedade, na direção dos trabalhos e na renda gerada pela atividade agrícola. O conceito de Agricultura familiar é amplo e tem várias discussões sobre o que é e quem fazem parte.

Diante do exposto, foi selecionada a cidade de Catolé do Rocha, localizada no semiárido paraibano, para ser estudado o seguinte problema de pesquisa: Existe relação entre a implementação da política pública do PRONAF com o desenvolvimento da agricultura local?

Partindo dessa realidade foi realizada uma pesquisa de campo nesse município a fim de compreender a importância da implementação do PRONAF e seus impactos socioeconômicos nas regiões rurais beneficiadas pelo programa do município de Catolé do Rocha-PB.

\section{MATERIAL E MÉTODOS}

Para tanto, o tipo de pesquisa escolhido para este trabalho, quanto a sua forma de abordagem, é a pesquisa qualitativa, por requerer uma maior proximidade do pesquisador com o campo investigado. Segundo Minayo (2009), a pesquisa qualitativa traz respostas a questões peculiares.

Esses conjuntos de fenômenos humanos estão relacionados à realidade social, ou seja, o mundo objetivo tem relação indissociável com a subjetividade do sujeito. E com relação aos objetivos deste estudo, utilizou-se uma pesquisa descritiva, por haver necessidade de descrever características de determinada população ou fenômeno ou estabelecimento de relações entre as variáveis (GIL, 2010).

Este artigo foi desenvolvido com a finalidade de compreender a importância da implementação do programa PRONAF e seus impactos socioeconômicos no município de Catolé do Rocha-PB. Este estudo foi caracterizado como uma pesquisa exploratória e descritiva, na medida em que tem seu objetivo pautado em descrever as características de determinado problema. Quanto ao método optou-se por um estudo de caso, visto que este tipo é o mais utilizado segundo o problema a ser estudado (AUTOR).

$\mathrm{O}$ instrumento de coleta de dados utilizado para o desenvolvimento do estudo foi a entrevista semiestruturada (apêndice 1), para que ocorra uma interação entre entrevistador-entrevistado, permitindo que os entrevistados se sintam a vontade para responderem aos questionamentos da forma que os mesmos acharem conveniente sobre a temática estudada.

Quanto à abordagem, esta pesquisa é considerada como de ordem qualitativa (Flick, 2009), no qual os dados da pesquisa serão obtidos a partir de entrevistas junto aos atores locais envolvidos na realidade dessa política pública, que serão constituídos por 1 agricultor familiar beneficiário do PRONAF , 1 representante pertencente à Secretaria de Agricultura do município, como também o representante da EMATER responsável pela assistência e suporte técnico aos agricultores pronafianos no município.

Foi utilizada uma análise de conteúdo dos dados fornecidos pelas entrevistas coletadas. Que segundo Minayo (2009), a análise de conteúdo é considerada um conjunto de técnicas de análise de comunicações que tem como objetivo de adquirir, indicadores, sejam eles quantitativos ou qualitativos, que sejam capazes de permitir a interpretação de resultados fornecidos pelo entrevistado. Trata-se de uma 
técnica usada para o tratamento de dados que busca a identificação daquilo que está sendo mencionado em torno de um tema específico (VERGARA 2008). Para melhor entendimento do conteúdo dessa pesquisa, foram transcritas algumas das falas mais relevantes para o entendimento do objeto de estudo por intermédio das falas dos entrevistados.

O município estudado foi o de Catolé do Rocha- PB, que situa-se na região Nordeste, na mesorregião do Sertão, a uma distância de $434 \mathrm{~km}$ da capital do estado, João Pessoa PB. Sua extensão territorial abrange uma área de 552, 112 $\mathrm{km}^{2}$ e conta com um número populacional de 28.759 habitantes, com uma pequena diferença nas quantidades entre sexo feminino e masculino, sendo 14.731 mulheres em detrimento do número de homens que somam 14.028, como mostram os dados do Instituto Brasileiro de Geografia e Estatística (IBGE) no censo de 2010.

No que se refere à agropecuária, o município de Catolé do Rocha, utiliza-se como referência as principais variáveis relacionadas à sua produção, tais como: número de cabeças dos principais rebanhos locais (bovino, caprino, ovino e suíno), produção de leite (em mil litros), total de aves (galinhas, pintos e aves afins), produção das principais lavouras exploradas no estado da Paraíba (IBGE, 2011).

Pode se deduzir pelo observado que a região que compreende Catolé do Rocha não apresenta destaque notável no referente a atividades econômicas no setor primário da economia, todas as atividades agropecuárias analisadas apresentam baixos índices em relação ao Estado (IBGE, 2011).

\section{Implementação do PRONAF no município}

Quanto à implementação e gestão dos recursos destinados ao meio rural, o município de Catolé do Rocha conta com uma unidade regional da EMATER-PB, a Secretaria de Agricultura do Município e instituições fomentadoras de acesso ao crédito que são: o Banco do Brasil e o Banco do Nordeste. A instituição EMATER compete à elaboração dos projetos para serem enviadas as instituições fomentadoras de crédito para ser viabilizados e aprovados, em seguida são encaminhados novamente para a EMATER, que consiste no acompanhamento das práticas desenvolvidas pelos agricultores familiares. Já a Secretaria de Agricultura do município trabalha em paralelo com os demais órgãos, visto que a mesma trabalha com programas complementares ao PRONAF, tais como atuar na coordenação da política agrícola do município, coordenar os programas voltados para a pecuária e garantir a população o acesso a alguns programas em que os recursos são repassados para serem fiscalizados pela Secretaria de Agricultura, dessa forma promovendo melhorias na geração de renda e consequentemente na qualidade de vida da população.

Em entrevista com o assessor do crédito rural no município, conseguimos informações que reforçam o cumprimento de algumas dessas atribuições. Ele caracteriza os atores responsáveis pela implementação do programa:

O acompanhamento desse programa no município é feito por instituições financeiras a partir dos bancos do Brasil e do Banco do Nordeste. Fica a cargo do pessoal da EMATER elaboraram as propostas e encaminham as instituições financeiras para a contratação, Dessa forma a implementação, assessoramento e o acompanhamento fica a cargo do pessoal técnico da EMATER (Assessor do Crédito Rural).

Heidemann (2009), mostra que a fase de implementação de políticas públicas tem sido entendida como consequência automática das decisões tomadas na etapa de formulação, para este autor, esta deve ser considerada uma oportunidade para se realizar o esforço de obter cooperação entre os atores envolvidos nessa implementação, dessa forma o que pressupõe que esta fase apresenta como característica a natureza participativa e dialógica.

Ao entrevistar o agricultor familiar para saber seu ponto de vista sobre a adesão e gestão dessa política pública o mesmo coloca que "Atualmente as dificuldades são poucas para o acesso ao crédito, a dificuldade que observo é a falta de profissionais técnicos para o acompanhamento das nossas atividades o que trariam mais benefícios para a atividade e para o programa".

Pode se observar que na atualidade há um aumento de informações que chegam aos agricultores rapidamente, fazendo com que os mesmos busquem participar dessa política pública que tanto beneficia a sociedade em geral e faz com que o homem do campo permaneça no campo gerando melhores condições de vida para sua família e trazendo alimentos de qualidade para a mesa dos consumidores. Dessa forma, o trabalho com a implementação dessa política ocorre de forma integrada trazendo benefícios para a população em geral.

A agricultura familiar apresenta destaque, necessitando de um maior suporte na implementação e gestão de políticas de assistência técnica e creditícia, buscando promover uma maior produtividade, como também maiores investimentos para proporcionar uma melhor qualidade de vida para o agricultor o que acarretara em produtos de qualidade e com melhores preços para os consumidores finais.

Quanto à gestão dessa política pública foram elencados alguns pontos falhos que foram apontados por todos os atores locais entrevistados. A secretaria de agricultura do município coloca como desafios a serem superados o montante de recursos disponibilizados para atender os agricultores que são limitados não atendendo a todos, outro aspecto falho é a falta de profissionais para fazer o acompanhamento de todos. Esses mesmos pontos são colocados pelo agricultor familiar, $\mathrm{o}$ assessor rural complementa em sua fala ao relatar.

Atualmente as dificuldades são poucas para o acesso ao crédito, a dificuldade que observo é a falta de profissionais técnicos para o acompanhamento das nossas atividades o que trariam mais benefícios para a atividade e para o programa. As sugestões são que o governo deveria aumentar a quantidade de dinheiro para ser emprestado aos agricultores familiares, contratar mais pessoas para atender mais pessoas e 
incentivar ainda mais a compra de produtos que tem origem na agricultura familiar (Agricultor Pronafiano).

Falta de abrangência na assistência técnica a todos os agricultores e a falta de fiscalização completa dos investimentos com o dinheiro do crédito. Enquanto que inúmeros são os pontos positivos dessa política pública são promoção da inclusão social, diversificação da produção, aumento na geração de emprego e renda, permite a participação de mulheres, jovens, indígenas e quilombolas que retiram da terra seu sustento (Assessor rural).

Os aspectos colocados pelos atores locais podem ser comprovados por Grisa (2012), ao afirmar que o programa visa especificamente o ajustamento de políticas públicas à realidade dos agricultores familiares, através do financiamento da produção agrícola familiar e de infraestrutura e serviços, e também a capacitação de técnicos e agricultores para desenvolverem da melhor forma a atividade que promove a permanência do agricultor no campo. Um problema que é observado no estudo é a falta de profissionais técnicos para suprir a demanda.

O acesso ao crédito na atualidade é considerado de fácil aquisição, houve uma diminuição na burocracia que dificultava essa aquisição. As condições na atualidade são mais bem favorecidas em função das exigências que se tornaram menores para o acesso olhando a condição que é inerente aos agricultores familiares, conforme a Secretaria de Agricultura.

Entre os desafios podem ser elencados alternativas para a convivência com adversidade climática, a resistência dos agricultores ao uso de novas e inovadoras tecnologias e a falta de interesse na diversificação de atividades, visto que os mesmos só estão preocupados com atividades que sejam garantias de lucro em curto prazo (Secretaria da Agricultura).

O PRONAF se caracteriza como uma política pública que ao ser bem implementada, pode trazer resultados satisfatórios para os agricultores familiares. Para isso, é importante que haja sempre um monitoramento, avaliação e caso necessário, ajustes na forma de implementação, para que o programa seja capaz de contribuir no desenvolvimento da Agricultura Familiar.

$\mathrm{O}$ agricultor familiar entrevistado coloca que passou a confiar mais nas políticas públicas, à medida que passou a ser valorizado com a contemplação de participar desse programa que tanto contribuiu para o desenvolvimento local e para a geração de renda para toda a família. Também foi colocado pela a Secretaria de Agricultura os benefícios para a população ao mostrar que:

O Programa traz muitos benefícios para os agricultores familiares, promovendo o acesso ao crédito rural com condições vantajosas, Principalmente para os mesmos, trazendo para os beneficiários, servindo para a diversificação das atividades, Garantindo renda para sua família (Secretaria de Agricultura).

Ambos os entrevistados afirmam que trabalham em parceria com outros órgãos tanto no âmbito municipal como estadual e federal dando como exemplo a parceria com diversas entidades dentre elas podem ser listadas o garantia safra a cunho municipal, a CONAB Companhia Nacional de Abastecimento a nível de governo federal, A EMEPA a nível estadual e os agentes financeiros que são os financiadores do programa.

\section{A comunicação sobre a política pública}

Um questionamento bastante relevante foi em relação à comunicação entre os atores que participam desse quadro de política pública e se existe algum tipo de capacitação ou parceria entre organizações para difundir novas tecnologias a fim de diversificar as atividades, tornando as mais competitivas. Foi relatado pelo assessor rural e pela Secretaria de Agricultura que:

São feito reuniões para divulgar o programa e excursões a áreas bem sucedidas para mostrar o sucesso, fazemos também à integração com outras regiões (tanto na área técnica como social). Capacitações são realizadas para os agricultores a custo zero para que eles desenvolvam o lado empreendedor e garantam o sustento de seus lares (Assessor Rural).

Reuniões são realizadas com líderes dos agricultores familiares com a finalidade de informar sobre as ações a nível local e estadual para que os mesmos não sofram com a estiagem, convivendo da melhor forma com esse fenômeno climático que atinge o Nordeste brasileiro, mas especificamente o semiárido (Secretaria de Agricultura).

Com base nas informações colhidas com a pesquisa é possível concluir que existe interação entre os atores locais e a implementação e decisão sobre a política pública do PRONAF, entretanto necessita-se um maior engajamento entre a Secretaria Municipal de Agricultura e a EMATER na realização de encontros mais frequentes que visem estimular a participação dos agricultores nas capacitações, que trarão para os mesmos melhores resultados como também diversificação de atividades

A secretária municipal de agricultura descreveu que os agricultores familiares são convidados para participar das ações que estão são planejadas pela secretaria em parceria com as instituições fomentadoras de créditos e ONGs que trabalham com a implementação dessa política no município, "segundo ela a participação dos agricultores é indispensável, pois através dela eles conseguem interagir com outras realidades e aprendem novas tecnologias". Ela também 
esclarece que existem reuniões mensais para construção de prioridades que são apontadas pelos mesmos como importantes para o desenvolvimento de suas atividades.

De acordo com Secchi, (2013), as políticas públicas assim formuladas, em conexão com os anseios de comunidades locais, em comum acordo com elas e com a responsabilidade distribuída de maneira justa em proporção ao acesso à informação e ao poder de cada indivíduo e instituição devem ter melhores resultados do que aquelas formuladas e implantadas de forma única, que são percebidas pela falta de comunicação ente os membros.

\section{O PRONAF e seus impactos socioeconômicos}

Muitos são os benefícios oriundos do crédito do PRONAF para os agricultores que para os atores locais tem mudado a realidade do campo, visto que essa política pública proporciona suporte para que o agricultor familiar possa permanecer no campo retirando dele de forma racional e sustentável os insumos necessários para o mesmo e para sua família. $\mathrm{O}$ assessor do crédito rural no município lista como benefícios:

Melhoria nas condições de
infraestrutura produtiva melhorada,
seguindo as atividades desenvolvidas na
propriedade. (Suprindo as necessidades
antes não atendidas por falta de recursos).
Permite a inclusão social (mulheres e jovens
rurais antes não contemplados, atualmente
são os principais beneficiários nos projetos
requeridos de acordo com a realidade local).
É um programa destinado a toda família
permite a fixação do homem no campo
(diminuição do êxodo rural). O homem do
campo está saindo do campo não mais pela
falta de políticas públicas e sim devido ao
aumento da violência do campo. Ocasionou
também a redução das invasões de terras,
devido à permanência do homem no campo.
Há também o casamento entre o programa e
outras políticas públicas complementares se
encaixam com o PRONAF, objetivando a
inclusão social da família oportunizando a
promoção de renda para todos (Assessor
Rural).

O agricultor familiar pronafiano tem muitas informações sobre a importância e os benefícios de terem acesso ao crédito disponibilizado pelo PRONAF, dessa forma surge algumas políticas públicas que trabalham em paralelo com essa política pública quando relata que:

O programa tem ajudado muito a nós agricultores familiares, visto que ele incentiva ao desenvolvimento do campo e gera renda para toda a família, através do desenvolvimento de várias atividades. O maior benefício que pode ser colocado é ter acesso ao credito para comprar a vista equipamentos e insumos para a propriedade como também direito a outros benefícios como comprar veículos com redução de impostos o que gera muitos benefícios para o deslocamento e desenvolvimento das atividades (Agricultor Pronafiano).

Segundo o agricultor entrevistado o mesmo afirma que melhorou sua autoestima, sua família passou a valorizar mais a vida simples existe no campo, começou a perceber que se pode ter uma vida digna e simples, fazendo o que gosta e promovendo melhores condições de vida para os meninos.

Neves, (2007) também revelou as dimensões e a heterogeneidade da agricultura familiar, destacando a importância deste segmento como política pública voltada para o homem do campo que atua na geração de emprego e renda, justificando assim a criação dessa política especial voltada especificamente para esta categoria que são os agricultores familiares.

\section{CONCLUSÕES}

Este artigo procurou compreender a importância da implementação da política pública do PRONAF, no desenvolvimento local da agricultura familiar no município de Catolé do Rocha no semiárido paraibano. Para se chegar aos dados pretendidos, foram realizadas entrevistas com 3 atores locais que são elementos fundamentais para a execução dessa política, aliada a leitura de alguns artigos que retratam análises de leis e decretos que correspondem ao PRONAF, com a finalidade de obter informações sobre a realidade do Programa no município.Com base nessas análises foi possível observar que a atuação do PRONAF no município, tem passado por grandes mudanças que contribuem para melhorar a vida dos agricultores familiares, influenciando no desenvolvimento da agricultura familiar do município, pois como já foi exposto muitos benefícios foram conseguidos para esse segmento da sociedade, necessitando de profissionais especializados para acompanhar e diversificar as atividades do homem do campo, e consequentemente conseguindo o desenvolvimento local de forma mais sustentável possível. Segundo os atores entrevistados, algumas ações podem ser viáveis na busca do desenvolvimento da agricultura familiar.

A implementação, pode ser entendida como sendo uma das fases da política pública em que a mesma se materializa, dessa forma, sendo um processo de execução das políticas o que resultaram na formulação e decisão da aplicabilidade da mesma. Segundo Secchi (2013). É preciso que haja uma maior interação da sociedade, para que a mesma procure ajudar os agricultores familiares na busca por benefícios.

O Estado deve procurar atender aos anseios dos agricultores avalie suas políticas públicas, melhorando sua implementação para fortalecer esse setor em suas necessidades específicas, proporcionando a todos a assistência técnica e acompanhamento das atividades diversificando-as. Deve questionar se o poder público busca meios que certamente não irão procurar resolver os problemas referentes à implementação da política pública, através da fiscalização e destinação de políticas complementares mais eficazes e que atendam a quem realmente necessita, aperfeiçoando as ações que já tiverem êxito para as condições de áreas específicas com desenvolvimento precário, como no caso do semiárido, utilizando tecnologias capazes de promoção da convivência do homem do campo com a seca; 
um aspecto deve ser levado em consideração que é o caso da realização de capacitações para a formação de mão de obra qualificada agregando valor ao produto final oriundo da atividade financiada pelo PRONAF.

Estudos futuros devem ser realizados tendo como objeto de estudo a implementação de políticas públicas que ampliem o entendimento dessa fase do ciclo de política voltado para a agricultura local para que outras inferências sejam realizadas sobre o tema estudado, pois essa pesquisa ficou limitada apenas a fase de implementação não levando em consideração a importância das demais fases.

\section{REFERÊNCIAS BIBLIOGRÁFICAS}

ARRETCHE, M. Dossiê agenda de pesquisa em políticas públicas. Revista Brasileira de Ciências Sociais, 18(51), 20-109, 2003.

BACEN - BANCO CENTRAL DO BRASIL. Manual do crédito Rural. 2009. Disponível em: <http://www4.bcb.gov.br>. Acesso em: 20 maio 2014.

BRASIL. (2009) Instituto Brasileiro de Geografia e Estatística (IBGE). Disponível em: <http://www.ibge.gov.br/cidadesat/topwindow.htm?1>. Acesso em: 15/10/2014

BRASIL. Instituto Brasileiro de Geografia e Estatística (IBGE). 2011. Disponível em: <http://www.ibge.gov.br/cidadesat/topwindow.htm?1>. Acesso em: 29/10/2014

DUQUE, J. G. O Nordeste e as lavouras xerófilas. Fortaleza: Banco do Nordeste, 1973.

FAUTH, E. Agricultura Familiar: evolução favorável em anos recentes. Revista FEE, 2008

FLICK, U. Introdução à pesquisa qualitativa. $3^{\text {a }}$ ed. Porto Alegre: Bookman/Artmed, 2009.

FOX, Charles J. Implementation research: why and how to transcend positivist me thodologies. In: PALUMBO, D. J.; CALISTA, D. J. Implementation and the policy process: opening up the black box. Greenwood Press, 1990.

FRANCA, C. Impactos da Globalização no Nordeste do Brasil: o caso da agricultura familiar no vale do submédio são francisco, pólo da fruticultura de juazeiro/Petrolina. Revista Opara: ciências contemporâneas aplicadas, 2013.

GIL, A. Como Elaborar Projetos de Pesquisa. 5. ed. São Paulo: Atlas, 2010.

GRISA, C. Políticas públicas para a Agricultura Familiar no Brasil: produção e institucionalização das idéias. Tese de doutorado em Ciências Sociais Em Desenvolvimento, Agricultura e Sociedade. Universidade Federal Fluminense. Rio de Janeiro, RJ, Brasil, 2012.
GUANZIROLLI, C. E. PRONAF dez anos depois: resultados e perspectivas para o desenvolvimento rural. Revista de Economia e Sociologia Rural, Rio de Janeiro, vol. 45, $n^{\circ}$ 02, p. 301-328, 2007.

GUANZIROLI, C. E. et .al. Agricultura familiar e reforma agrária no século XXI. Rio de Janeiro: Garamond, 2001.

HEIDEMANN, F. G. Do sonho do progresso às políticas de desenvolvimento. In: HEIDEMANN, F. G., SALM, J. F. (Orgs). Políticas públicas e desenvolvimento: bases epistemológicas e modelos de análise. Brasília-DF, UNB, 340p., 2009.

HILL, M.; HUPE, P. Implementing public policy. London: Sage Publications Ltd.,

2002

LAMARCHE, H. A agricultura familiar. Campinas: UNICAMP, 1993.

MATIAS-PEREIRA, J. Manual de gestão pública contemporânea . 4. ed. São Paulo: Atlas, 2012.

MATTEI, L. PRONAF 10 anos: mapa da produção acadêmica. Série Estudos 12 NEAD. MDA, Brasília, 2006.

MINAYO, M. Pesquisa Social: Teoria, Método e Criatividade. 28. ed. Petrópolis: Vozes, 2009.

Ministério do Desenvolvimento Agrário (MDA). Programa de Aquisição de Alimentos. 2011. Recuperado em 27 setembro, 2014 de http://www.mds.gov.br/segurancaa limentar/alimentoseabastecimento/paa

Ministério do Desenvolvimento Agrário (MDA). Programa Nacional de Fortalecimento da Agricultura Familiar. 2012. Recuperado em 28 de setembro, 2014 de http://portal.mda. gov.br/portal/saf/programas/pronaf.

NEVES, D. P. Agricultura Familiar: quantos ancadouros. In: FERNANDES, B. M.; MARQUES, M. I. M.; SUZUKI, J. C. Geografia Agrária: teoria e poder. $1^{\mathrm{a}}$ ed.São Paulo: Expressão Popular, p. 211- 270, 2007.

RUA, M. G. Políticas Públicas. Florianópolis: Departamento de Ciências da Administração / UFSC; [Brasília]:CAPES: UAB, 2009.

SCHNEIDER, A. L. Pesquisa avaliativa e melhoria da decisão política: evolução histórica e guia prático. In: HEIDEMANN, F.G., SAlM, J. F. (Orgs). Políticas públicas e desenvolvimento: bases epistemológicas e modelos de análise. Brasília-DF, UNB, 340p., 2009

SABOURIN, E. Que política pública para a agricultura familiar no segundo Governo Lula. In: Sociedade e Estado, Brasília, vol. 22, no 3, p. 715-751. Set/dez, 2007. 
SECCHI, L. Políticas Públicas: conceitos, esquemas de análise, casos práticos. Florianópolis: Cengape, 2010.

SECCHI, L. Políticas Públicas: Conceitos, esquemas de análise, casos práticos. 2. ed. São Paulo, Cengage Learning, 2013. 119 p.

SOUZA, C. Estado da arte da pesquisa em políticas públicas. In: HOCHMAN, G.; ARRETCHE, M.; MARQUES, E. (Org.). Políticas públicas no Brasil. Rio de Janeiro: Fiocruz, p. 65-86, 2007.

SOUZA, C. Políticas Públicas: Uma revisão da literatura. In Sociologias, $\mathrm{n}^{\circ} 16$, Porto Alegre, 2006.

SOUSA, M. L. O território: sobre espaço e poder, autonomia e desenvolvimento. In: CASTRO, I. E.; GOMES, P. C. C.; CORRÊA, R. L. Geografia: conceitos e temas. Rio de Janeiro; Bertrand Brasil, p. 77-116, 1995.

TINOCO, Sonia Terezinha Juliatto. Conceituação de Agricultura Familiar - uma revisão bibliográfica. 2005. Disponível em: <http://www.cati.sp.gov.br/Cati/_tecnologias/teses /TESESONIATINOCO.pdf >. Acesso em 10 de Novembro de 2014.

VERGARA, S. Métodos de Pesquisa em Administração. 3. ed. São Paulo: Atlas, 2008.

VILLA, M. A. Vida e morte no Sertão: história das secas no Nordeste nos Séculos IX e XX. 1. ed. São Paulo: Ática, 2000 . 